\title{
SELECCIÓN DE PORTAFOLIOS DE INVERSIÓN SOCIALMENTE RESPONSABLES USANDO EL MÉTODO DE LAS RESTRICCIONES Y LA TÉCNICA MULTICRITERIO PROCESO ANALIITICO JERÁRQUICO
}

\author{
Lady Mayerly Bernard SuÁrez ${ }^{1}$ \\ $\triangle$ NÉSTOR RAÚl ORTIZ PIMIENTO ${ }^{2}$ \\ JuAn Benjamín Duarte Duarte ${ }^{3}$
}

\section{RESUMEN}

En este artículo se presenta un procedimiento que permite apoyar el proceso de decisión de los inversionistas al seleccionar un portafolio que cumpla con sus expectativas económicas y con aquellas relacionadas con Responsabilidad Social Empresarial (RSE). Para ello, se consideran criterios de rentabilidad y riesgo como medidas económicas que, abordadas desde el método de las restricciones, dan como resultado una serie de portafolios eficientes que se emplean como alternativas para la aplicación de la técnica multicriterio AHP (sigla en inglés), la cual permite establecer el portafolio que cumple con criterios de gobierno corporativo, relaciones con colaboradores, medio ambiente y relaciones con la comunidad como medidas de RSE. El procedimiento se aplica en la selección de portafolios de inversión para acciones del mercado bursátil colombiano, dando como resultado que el portafolio que mejor cumple con los criterios establecidos en este artículo para RSE también es el de mínimo riesgo.

PALABRAS CLAVE: Portafolios de inversión; Markowitz; Multiobjetivo; Multicriterio; Responsabilidad Social Empresaria (RSE).

\section{SELECTION OF SOCIALLY RESPONSIBLE INVESTMENT PORTFO- LIO USING A RESTRICTIONS METHOD AND A MULTI-CRITERIA ANALYTIC HIERARCHY PROCESS TECHNIQUE}

\section{ABSTRACT}

This paper presents a procedure to support the decision making process of the investors to select a portfolio that meets their expectations, when they are related with both economic and corporate social responsibility (CSR) criteria. Rentability and risk criteria were considered as economic measures; which addressed from the method of constraints resulted in a series of efficient portfolios that were used as different alternatives for the use of the AHP multi criteria tech-

1 Ingeniera industrial. Universidad Industrial de Santander (UIS). Bucaramanga, Colombia.

2 Ingeniero industrial, Especialista en Gestión Tecnológica y Docencia Universitaria y Magíster en Ingeniería de Sistemas, Universidad Industrial de Santander (UIS) Bucaramanga, Colombia.

3 Ingeniero industrial y Especialista en Sistemas, Gestión de la Producción, Docencia Universitaria, Universidad Industrial de Santander (UIS) Bucaramanga, Colombia. Magíster y Doctor en Finanzas de Empresa, Universidad Complutense de Madrid, España.

Autor de correspondencia: Duarte-Duarte, J.B. (Juan

Benjamin). Universidad Industrial de Santander. Cra 27 calle 9. Bucaramanga, Colombia. / Tel.: (571) 6344000. Correo electrónico: jbduarted@hotmail.com
Historia del artículo:

Artículo recibido: 27-X-2014 / Aprobado: 27-VI-2015

Disponible online: 30 de octubre de 2016

Discusión abierta hasta noviembre de 2016 
nique to arrive at the portfolio that meets the criteria related with corporate governance, relations with collaborators, environmental consciousness and relations with the community, all measured from the CSR perspective.The procedure was applied to select investment portfolios from the Colombian stock market and it was found that the portfolio that met the CSR criteria proposed in this paper was also the one with the minimum risk.

KEYWORDS: Investment Portfolios; Markowitz; Multiobjective; Multi-criteria; Corporate Social Responsibility.

\section{SELEÇÃO DE CARTEIRAS DE INVESTIMENTO SOCIALMENTE RESPONSÁVEIS, UTILIZANDO O MÉTODO DE RESTRIÇÕES E A TÉCNICA DE MULTICRITÉRIO PROCESSO ANALÍTICO JERARQUICO}

\section{RESUMO}

Este artigo descreve um procedimento que permite a apoiar o processo de tomada de decisão dos investidores para selecionar um portfólio que atenda às expectativas econômicas e as relacionadas com a Responsabilidade Social Empresarial (RSE). Para isso, se considera critérios de risco e retorno como medidas econômicas, que tomadas desde o método das restrições, dão como resultado uma série de carteiras eficientes que são utilizados como alternativas para a implementação da técnica multi-criterio AHP (sigla em inglês) que permite estabelecer o portfólio que atende aos critérios do governo corporativo, relações com funcionários, meio ambiente e relações com a comunidade como medidas de RSE. O procedimento é aplicado na seleção de carteiras de investimento para ações do mercado colombiano, dando como resultado que a carteira que melhor atenda os critérios estabelecidos no presente artigo para RSE também é o do risco mínimo.

PALAVRAS-CHAVE: carteiras de investimento; Markowitz; multi-objetivo; multi-criterio; a responsabilidade social empresarial (RSE).

\section{INTRODUCCIÓN}

Cada día el mercado de capitales adquiere mayor importancia para el desarrollo económico de un país, debido a que se ha convertido en un medio alternativo para la financiación de empresas y gobierno, así como una alternativa de inversión. No obstante, ante la posibilidad de encontrar múltiples opciones de títulos, se dificulta el proceso de establecer en qué tipo de valores es pertinente invertir y la cantidad de dinero que se destinará para este fin. Por ello en la literatura científica se han planteado diversos modelos, en su mayoría cuantitativos, para abordar este tipo de decisiones y representar matemáticamente la realidad. Entre los métodos cuantitativos utilizados se encuentra el modelo «Media-Varianza» planteado por Markowitz, el cual se ha convertido en la base de la teoría de portafolios y del cual se han derivado otros modelos que buscan una solución óptima o, por lo menos, factible al problema de la selección de portafolios de inversión.

Asimismo, se destaca que en la actualidad el tema de responsabilidad social empresarial (RSE) ha cobrado especial importancia en el ámbito financiero; para algunos inversores saber que las empresas donde invierten su dinero tienen un compromiso con la sociedad y el medio ambiente podría ser gratificante, ya que con 
sus inversiones contribuirán indirectamente al desarrollo sustentable del país. No obstante, modelar matemáticamente estas características empresariales en el proceso de decisión de portafolios de inversión es un tema complejo, pues estas son principalmente cualitativas. Pese a la complejidad del modelamiento matemático, algunos autores han establecido técnicas multicriterio para incorporar en distintos procesos de decisión varias consideraciones cualitativas que permitan encontrar una solución que se adecúe a las necesidades del decisor.

Con el fin de abordar el problema de selección de portafolios de inversión involucrando la perspectiva de RSE, este artículo se propone un procedimiento que consta de dos fases: la primera, basada en el método de las restricciones y que apoya el análisis de las medidas cuantitativas de rentabilidad y riesgo; y la segunda, fundamentada en el proceso analítico jerárquico (AHP) que permite apoyar el proceso de decisión cuando se evalúan las características relacionadas con RSE, como gobierno corporativo, relaciones con colaboradores, medioambiente y relaciones con la comunidad.

\section{REVISIÓN DE LITERATURA}

El origen de la gran mayoría de los modelos de selección de carteras es el de Harry Markowitz, dado a conocer en parte en 1952 y de manera más completa en 1959; también es llamado el modelo «Media-Varianza» y se ha convertido en la base de la teoría moderna de portafolios, además que ha contribuido a múltiples desarrollos y derivaciones que proporcionan un marco conceptual para la búsqueda de una solución óptima o por lo menos factible al problema de selección de portafolios de inversión.

El modelo presentado por Markowitz se fundamenta en las siguientes hipótesis (Franco, Avendaño y Barbutín, 2011):

- El rendimiento de cualquier título o portafolio es considerado una variable aleatoria, para la cual el inversionista estima una distribución de probabilidad para el periodo de estudio. El valor esperado de la variable aleatoria es utilizado para cuantificar la rentabilidad de la inversión.

- La varianza o la desviación estándar son utilizadas para medir la dispersión como medida del riesgo de la variable aleatoria rentabilidad; esta medición debe realizarse en forma individual, a cada activo y a todo el portafolio.

- La conducta racional del inversionista lo lleva a preferir la composición de un portafolio que le represente la mayor rentabilidad para determinado nivel de riesgo, o el mínimo riesgo para un determinado nivel de rentabilidad.

- La elección de elementos diversificados (que difieren en sus características) permite equilibrar las pérdidas y ganancias que se tienen con los distintos títulos valores.

A partir de los anteriores supuestos, se establece un problema de programación matemática multiobjetivo con el fin de maximizar el rendimiento y minimizar el riesgo, lo cual permitirá satisfacer, en cierta medida, las preferencias del inversionista. Debido a que cada inversionista tendrá diferentes preferencias en cuanto a rendimiento o riesgo, no se puede hablar de preferencias exactas. Sin embargo, todas las elecciones que sean tomadas deberán estar en la frontera eficiente; la cual se define como el conjunto de portafolios eficientes que para determinados niveles de rendimiento, no existen otros portafolios con menor riesgo e igual o mayor rendimiento; o dado varios niveles de riesgo, no existen portafolios con mayor rendimiento e igual o menor riesgo (Minutti, 2010).

Con la definición de la frontera eficiente, el inversor podrá establecer, de acuerdo a sus preferencias y actitud ante el riesgo, el portafolio que más le convenga. De esta forma, el modelo de Markowitz consiste principalmente en dos etapas: en primer lugar, determinar el conjunto de portafolios eficientes y posteriormente, escoger de este conjunto, el portafolio que cumple mejor con sus expectativas.

Sin embargo, el modelo Markowitz se ha visto limitado en la práctica debido a la complejidad matemática del método. Por una parte, al ser un 
programa cuadrático paramétrico, el algoritmo de resolución es complejo; por otra, el número de estimaciones de rentabilidades esperadas, varianzas y covarianzas a realizar es muy elevado. Igualmente, algunos autores han considerado relevantes otras características del modelo como: que supone la perfecta divisibilidad de los títulos valores seleccionados, que se va a invertir todo el capital disponible, que no es posible endeudarse para incrementar la inversión y además, no proporciona ninguna herramienta para que el inversor valore su actitud ante el riesgo y deduzca su función de utilidad, necesaria para la elección de su cartera óptima (Mendizabal, Miera y Zubia, 2002). Adicionalmente, se ha considerado que el empleo de parámetros históricos como estimadores de los parámetros esperados introduce sesgos importantes que proporcionan carteras concentradas en pocos títulos y que resultan poco atractivas para los inversores.

No obstante, para contemplar varias de estas características, algunos han planteado la inclusión de restricciones al modelo original relacionadas con costos de transacción y que limiten el porcentaje máximo del presupuesto que puede destinarse a cada título (Mendizabal, Miera y Zubia, 2002). Otros como Black y Litterman proponen un modelo basado en métodos bayesianos para valorar la actitud ante el riesgo de los inversores. (Franco, Avendaño y Barbutín, 2011).

En general, el principal aporte del modelo de Markowitz para la selección de un portafolio óptimo, de acuerdo con los objetivos del inversor, se encuentra en su utilidad para recoger los aspectos fundamentales que deben guiar a un inversionista racional en la elección de la composición de su portafolio. Este proceso inicia con la verificación de la naturaleza de cada activo individualmente, terminando con la decisión final sobre el portafolio óptimo.

Posterior a este modelo se han propuesto diversos modelos alternativos, que pueden ser de tipo lineal, no lineal, determinísticos, estocásticos y emplear otros paradigmas como maximizar la ganancia esperada sujeta a un cierto nivel de riesgo o, incluso, optimizar una combinación parametrizada de ganancia y riesgo (Fernández, 2008). Entre estos se cuentan los trabajos realizados por Branke, et al. (2009) y Subbu, et al. (2005), donde se determina también la frontera de carteras eficientes.

Adicionalmente, el problema ha sido resuelto por medio de algoritmos llamados evolutivos que se basan en diferentes heurísticas y meta-heurísticas como Algoritmos Genéticos, Búsqueda Tabú y Recocido Simulado. En estos planteamientos multiobjetivo, el riesgo y el rendimiento no siempre se calculan como se plantea en el modelo de Markowitz, y en algunos otros se utilizan restricciones como el precio de venta (Zavala, et al., 2009).

Asimismo, se puede resaltar que las técnicas multiobjetivo también han abordado, aunque no en gran amplitud, el tema de Inversión Socialmente Responsable. Cabe resaltar el trabajo desarrollado por Charnes y Cooper (1961) relacionado con la Programación por Metas (Goal Programming) que tiene en cuenta las preferencias del inversor reflejadas, de un lado, en la fijación de niveles aceptables de rentabilidad, riesgo y Responsabilidad Social Empresarial y, de otro, en la ordenación de las funciones objetivo por su importancia relativa para el inversor, con la cual se establecen entre las mismas un sistema de prioridades excluyentes e incluso ponderaciones dentro de cada nivel de prioridad, si hubiere lugar (Antomil, Cañal y Rodríguez, 2008). Para hacer aplicable esta técnica se han establecido índices que puedan medir la Responsabilidad Social de un portafolio de inversiones; sin embargo, son muy escasos los trabajos relacionados con estos. Según Bilbao et al. (2009), entre estos trabajos se cuentan los de Basso y Funari (2003), Barrachini (2004), Barnett y Salomon (2006), Kempf y Osthoff (2008).

De igual forma, algunos autores han planteado diversos modelos multicriterio para la selección de portafolios que consideren criterios relacionados con la generación de riqueza, la gerencia financiera, las medidas de desempeño, la gestión de portafolios, la evaluación del stock, el riesgo crediticio, etc. $\mathrm{u}$ otros referentes a inversiones socialmente responsables, que contemplan características de índole social, medioambiental y/o éticas. 
El trabajo de Hallerbach et al., realizado en el año 2004, es uno de los pocos donde se aplican técnicas multicriterio a la selección de carteras de fondos socialmente responsables (Antomil, Cañal y Rodríguez, 2008).

Del mismo modo, en la actualidad se pueden encontrar diversos métodos multicriterio con bases en la programación multiobjetivo, relaciones de sobreclasificación, los métodos ELECTRE y PROMETHEE, la valoración de funciones de utilidad y sistemas expertos (modelos de regla de decisión), que permiten la selección de portafolios a la luz de diversos criterios como los mencionados en párrafos anteriores (Fontalvo, Morelos y Vergara, 2012). Entre las técnicas multicriterio que han planteado el problema de la selección de portafolios de inversión se encuentran UTASTAR y AHP.

A pesar de la extensa literatura planteada sobre el tema de selección y optimización de portafolios de inversión, algunos inversionistas no han encontrado herramientas que se puedan ajustar a sus intereses particulares en cuanto a la elección de estos portafolios; tal es el caso de inversores cuya preocupación por cuestiones relacionadas con RSE ha aumentado en los últimos años. Por lo tanto, con la propuesta metodológica planteada en este artículo y la cual está basada en la inclusión simultánea de técnicas cuantitativas y cualitativas, se pretende construir un procedimiento que apoye la decisión de estos inversores socialmente responsables en la búsqueda de una cartera que pueda cumplir con sus expectativas.

\section{METODOLOGÍA}

Se propone un procedimiento para la selección de portafolios de inversión que considere, además de las tradicionales medidas de rentabilidad y riesgo, cuestiones de Responsabilidad Social Empresarial. Para ello se establecen las actividades que se describen a continuación:

\subsection{Fase 1: optimización multiobjetivo}

En el diagrama de flujo que se presenta en la Figura 1 se relacionan las actividades que se llevan a cabo en la primera fase del procedimiento, asociadas a la optimización multiobjetivo.

\subsection{Fase 2: optimización multicriterio}

Construida la frontera eficiente, el inversor, de acuerdo a su perfil de riesgo (bajo, medio o alto), establece la cantidad de alternativas o portafolios que llevará a un posterior análisis teniendo en cuenta la técnica multicriterio AHP y a la luz de criterios de RSE como gobierno corporativo, relaciones con colaboradores, medio ambiente y relaciones con la comunidad.

Para la aplicación de la técnica AHP se establece el grado de compromiso con la RSE de cada uno de los emisores de los títulos valores seleccionados para el portafolio. Para ello:

A. Se verifica en cada uno de los informes, reportes o memorias de sostenibilidad, las iniciativas que han adelantado los emisores de estos títulos valores en materia de los criterios de RSE definidos.

B. Con base en estas iniciativas, se determina una lista de chequeo con una cantidad determinada de factores que pueden soportar el compromiso de estas empresas con los criterios antes mencionados.

C. Para cada criterio se establece un número máximo de factores y se procede a comprobar si existen o no iniciativas que los respalden. Si existen iniciativas se marca la lista de chequeo con un 1, en caso contrario con un 0 .

D. Se suman para cada empresa y para cada criterio, las celdas marcadas con 1 y con ello se establece un puntaje, como se muestra en la Tabla 1.

E. Se promedian los puntajes de las empresas del portafolio para cada criterio y se determina el porcentaje de cumplimiento del promedio respecto su máximo puntaje.

F. Para establecer el grado de importancia de un criterio respecto a otro, se tienen en cuenta las diferencias en sus porcentajes de cumplimiento y la escala fundamental pareada definida por Saaty. Para ello, se realiza una matriz $4 \times 4$ como se muestra en la Tabla 2. 
Figura 1. Diagrama de flujo de la primera fase del procedimiento: optimización multiobjetivo

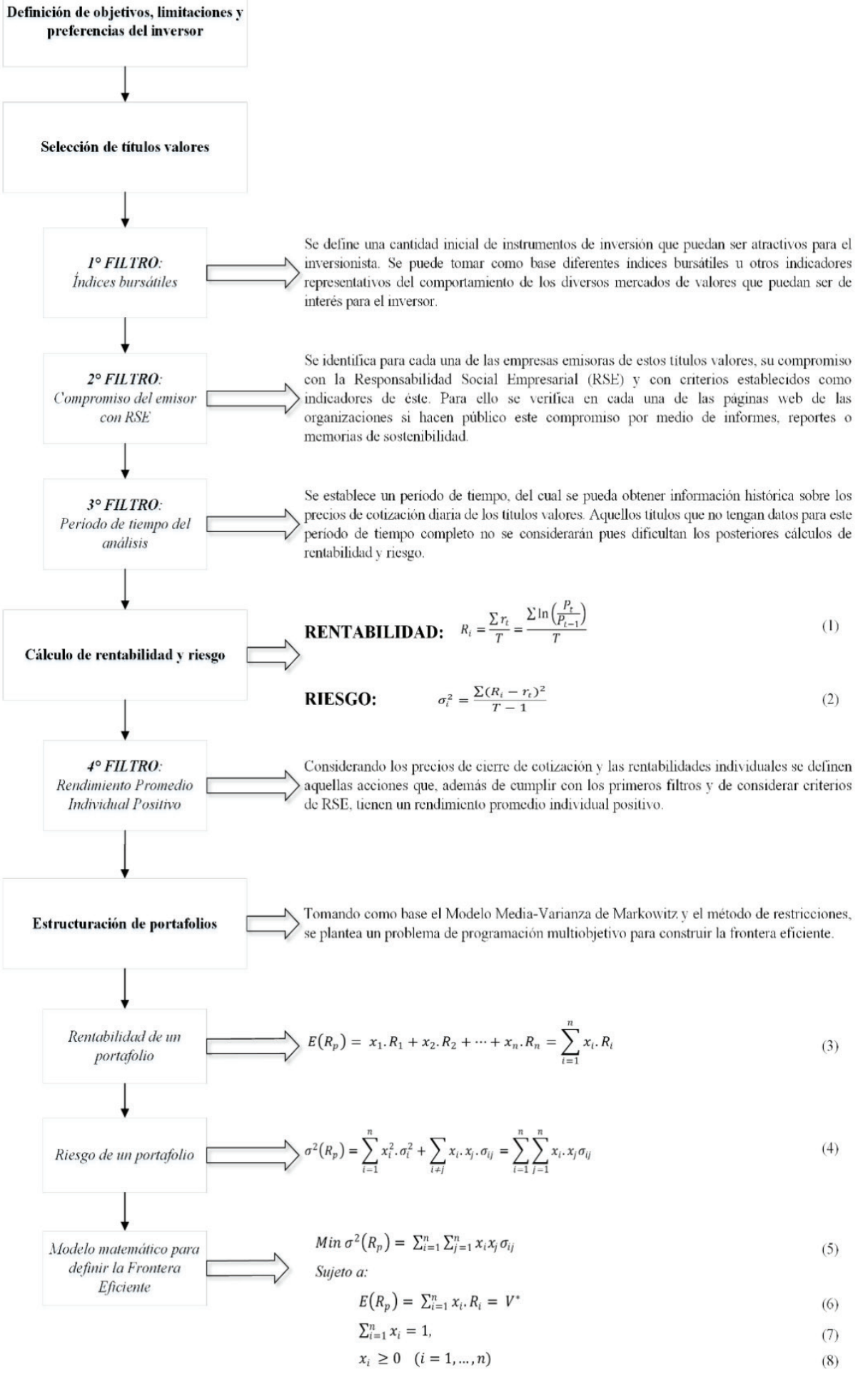




\begin{tabular}{|c|c|c|c|c|}
\hline \multicolumn{5}{|c|}{ Tabla 1. Puntaje de cada empresa } \\
para cada criterio \\
\hline Empresas & $\begin{array}{c}\text { Gobierno } \\
\text { corporativo }\end{array}$ & $\begin{array}{c}\text { Relaciones con } \\
\text { colaboradores }\end{array}$ & $\begin{array}{c}\text { Medio } \\
\text { ambiente }\end{array}$ & $\begin{array}{c}\text { Relaciones } \\
\text { con la } \\
\text { comunidad }\end{array}$ \\
\hline Empresa 1 & & & & \\
\hline Empresa 2 & & & & \\
\hline$\vdots$ & & & & \\
\hline Empresa n & & & & \\
\hline $\begin{array}{c}\text { Puntaje } \\
\text { promedio }\end{array}$ & & & & \\
\hline Máximo & & & & \\
\hline $\begin{array}{c}\text { \% de cum- } \\
\text { plimiento }\end{array}$ & & & & \\
\hline
\end{tabular}

Tabla 2. Diferencias entre porcentajes de cumplimiento de los criterios de RSE

\begin{tabular}{|l|l|l|l|l|}
\hline & $\begin{array}{c}\text { Gobierno } \\
\text { corporativo }\end{array}$ & $\begin{array}{c}\text { Relaciones } \\
\text { con colabora- } \\
\text { dores }\end{array}$ & $\begin{array}{c}\text { Medio } \\
\text { ambiente }\end{array}$ & $\begin{array}{c}\text { Relacio- } \\
\text { nes con } \\
\text { Ia co- } \\
\text { munidad }\end{array}$ \\
\hline $\begin{array}{l}\text { Gobierno } \\
\text { corporativo }\end{array}$ & & & & \\
\hline $\begin{array}{l}\text { Relaciones } \\
\text { con } \\
\text { colaboradores }\end{array}$ & & & & \\
\hline $\begin{array}{l}\text { Medio } \\
\text { ambiente }\end{array}$ & & & & \\
\hline $\begin{array}{l}\text { Relaciones } \\
\text { con la } \\
\text { comunidad }\end{array}$ & & & & \\
\hline
\end{tabular}

G. Si el porcentaje de cumplimiento del criterio 1 (Gobierno corporativo) es mayor que el porcentaje de cumplimiento del criterio 2 (Relaciones con colaboradores), se considera de mayor importancia el criterio 1; de la misma forma con los demás criterios. De acuerdo con la magnitud de la diferencia, se establece el puntaje en la escala fundamental pareada, teniendo en cuenta lo planteado en la Tabla 3.

H. Teniendo en cuenta el puntaje de cada empresa para cada criterio (Tabla 1) y los pesos porcentuales de cada título valor en cada portafolio (resultado de la frontera eficiente), se establece el puntaje promedio ponderado de cada una de las alternativas o portafolios a la luz de cada criterio.

I. Para definir el grado de importancia de un portafolio respecto a otro, se tienen en cuenta las

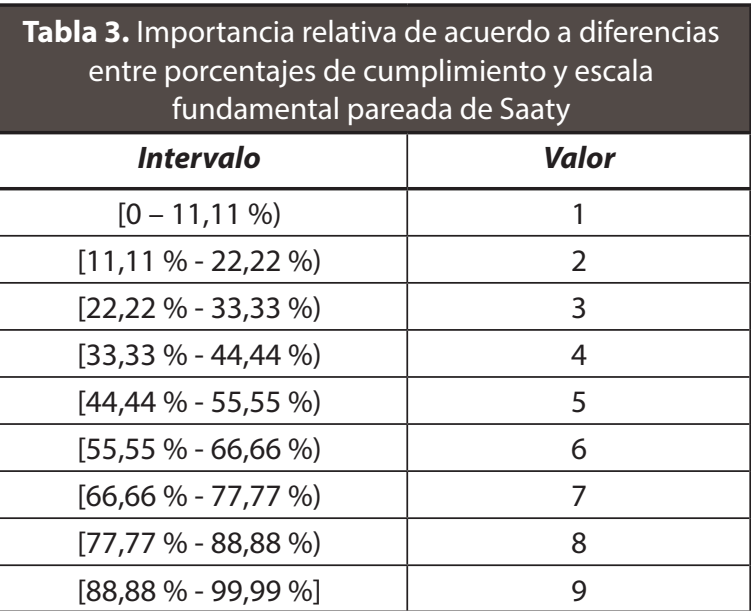

diferencias en sus porcentajes de cumplimiento y la escala fundamental pareada (Tabla 3). Para ello, se realiza una matriz pxp para cada criterio como se muestra en la Tabla 4.

\begin{tabular}{|c|c|c|c|}
\hline \multicolumn{5}{|c|}{$\begin{array}{c}\text { Tabla 4. Diferencias entre porcentajes } \\
\text { de cumplimiento de los portafo } \\
\text { lios para cada criterio de RSE }\end{array}$} \\
\hline & Portafolio 2 & $\ldots$ & Portafolio $p$ \\
\hline Portafolio 1 & & & \\
\hline Portafolio 2 & & & \\
\hline$\vdots$ & & & \\
\hline Portafolio $\mathrm{p}$ & & & \\
\hline
\end{tabular}

En esta etapa se utiliza el programa Expert Choice basado en el Proceso Analítico Jerárquico (AHP) y, como resultado, se presentan al inversor las alternativas o portafolios que escogió para su decisión final en orden de prioridad bajo consideraciones de RSE.

\section{RESULTADOS: CASO DE ESTUDIO}

El procedimiento planteado en este artículo se aplica al caso de la Bolsa de Valores de Colombia, bajo las siguientes consideraciones:

\subsection{Fase 1: optimización multiobjetivo}

- Se analizan títulos financieros de renta variable. 
A. Definición de objetivos, limitaciones y preferencias del inversor

- Se establece un perfil socialmente responsable de bajo riesgo.

B. Selección de los títulos valores en los cuales se realizará la inversión

- En el primer filtro se toma como referente el Índice General de la Bolsa de Valores de Colombia (IGBC), específicamente la canasta establecida para el trimestre agosto-octubre de 2013, la cual cuenta con 41 títulos, considerando que este índice mide de manera agregada la evolución de los precios de las acciones más representativas del mercado colombiano en función de su rotación y frecuencia.

- Con el fin de atender el interés del presente trabajo en abordar el problema de selección de portafolios de inversión involucrando la perspectiva de RSE, se define el segundo filtro mediante el cual se consideran los activos financieros cuyos emisores cuentan con un informe, reporte o memoria de sostenibilidad donde hacen públicas las iniciativas llevadas a cabo durante el año 2012 para soportar su compromiso con la RSE y, específicamente, con los cuatro ámbitos o criterios definidos en este artículo. Como resultado de este filtro el número de acciones se reduce a 30 .

- En el tercer filtro, se seleccionan aquellas acciones que cotizan en la bolsa hace 2 años o más. Como resultado de este filtro, se cuenta con 22 acciones. Es importante destacar que para efectos del presente ejercicio se tomó un horizonte de tiempo de dos años (octubre de 2011 a octubre de 2013), ya que la mayoría de las empresas obtenidas en el filtro anterior ha venido presentando informes de su compromiso con el tema de RSE desde hace poco tiempo. Igualmente, Fernández (2008), Zavala (2009) y Mendizábal, Miera y Zubia (2002) toman como referente en sus trabajos de investigación períodos entre 1 y 2 años para la construcción del Modelo Markowiz o modelos derivados del mismo. Este periodo relativamente corto podría generar sesgos en la información y en los resultados esperados, por tal motivo, para la aplicación de este procedimiento en un mercado más desarrollado se sugiere tomar un período más largo.

- Con el objetivo de buscar que la frontera eficiente a construir genere rendimientos positivos, en el cuarto y último filtro se toman los títulos que tienen un rendimiento promedio individual mayor a cero; como resultado se toman solamente 14 acciones que serían: Ecopetrol (ECOPETROL), Grupo Inversiones Suramericana (GRUPOSURA), Almacenes Éxito S.A. (ÉXITO), Canacol Energy Ltd. (CNEC), Grupo Aval Acciones y Valores S.A. (PFAVAL y GRUPOAVAL), Grupo Nutresa S.A. (NUTRESA), Corporación Financiera Colombiana S.A. (CORFICOLCF y PFCORFICOL), Empresa de Energía de Bogotá S.A. E.S.P. (EEB), Banco de Bogotá S.A. (BOGOTÁ), Isagen S.A. E.S.P. (Isagen), Organización de Ingeniería Internacional S.A. (ODINSA) y Helm Bank S.A. (PFHELMBANK).

C. Estructuración de portafolios que cumplan con los requisitos del inversor

- Se realizan los cálculos de rentabilidad y riesgo de las acciones obtenidas a partir de la aplicación de los filtros anteriores, considerando el promedio aritmético y la varianza de las rentabilidades diarias, dando como resultado las matrices de dominancia y de covarianzas que se muestran en las Tablas 5 y $\mathbf{6}$, teniendo en cuenta que en el cálculo del riesgo de un portafolio no solo influye el promedio ponderado de las desviaciones de cada activo sino que también incide la covarianza entre los mismos. Así las cosas, una covarianza negativa como la que presentan acciones como ÉXITO y PFCORFICOLF, ÉXITO e Isagen, PFCORFICOLF e Isagen, PFCORFICOLF y PFHELMBANK, EEB y ODINSA, PFHELMBANK y ODINSA, supone, en cierto modo, una compensación del riesgo del portafolio que las incluya, dado que mientras la rentabilidad de una acción decrece, un incremento en la rentabilidad de la otra podría equilibrar la cartera. 


\begin{tabular}{|c|c|c|c|c|c|c|c|c|c|c|c|c|c|c|}
\hline & 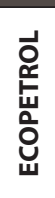 & 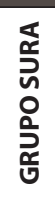 & 옳 & $\underset{\frac{\mathbf{L}}{\Delta}}{\stackrel{\vec{\alpha}}{\mathbf{a}}}$ & 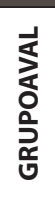 & 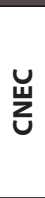 & 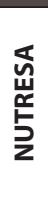 & 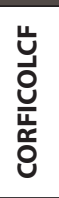 & 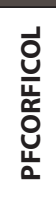 & 出 & 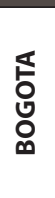 & $\begin{array}{l}\bar{\Xi} \\
\stackrel{g}{\Xi} \\
\underline{\underline{g}}\end{array}$ & $\begin{array}{l}\text { 玄 } \\
\text { oิ }\end{array}$ & 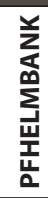 \\
\hline PROMEDIO & 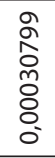 & 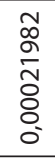 & $\begin{array}{l}\hat{m} \\
\stackrel{\infty}{0} \\
\varnothing \\
\delta \\
0 \\
0\end{array}$ & 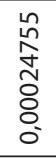 & 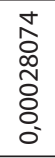 & $\begin{array}{l}\tilde{Z} \\
\text { ò } \\
\text { oे } \\
\tilde{O} \\
0 \\
0\end{array}$ & 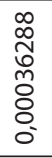 & 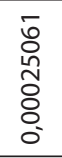 & 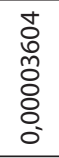 & 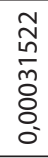 & 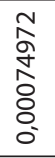 & 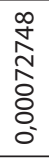 & $\begin{array}{l}8 \\
\varnothing \\
\varnothing \\
\varnothing \\
0 \\
0\end{array}$ & 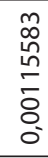 \\
\hline VARIANZA & \begin{tabular}{l}
$\circ$ \\
\multirow{f}{\infty}{} \\
$\delta$ \\
$\delta$ \\
0 \\
0
\end{tabular} & $\begin{array}{l}\stackrel{+}{N} \\
\infty \\
\infty \\
\delta \\
0 \\
0\end{array}$ & 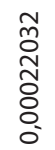 & $\begin{array}{l}\hat{\sigma} \\
\bar{\sigma} \\
\bar{\delta} \\
\delta \\
0\end{array}$ & 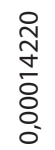 & $\begin{array}{l}\bar{\delta} \\
\text { வे } \\
\text { İ } \\
\bar{\sigma} \\
0\end{array}$ & 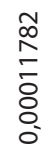 & $\begin{array}{l}\underset{N}{\infty} \\
\stackrel{\infty}{8} \\
\stackrel{0}{0} \\
0\end{array}$ & $\begin{array}{l}\frac{\infty}{\dot{\sigma}} \\
\frac{\infty}{\delta} \\
\frac{0}{0}\end{array}$ & 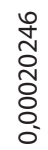 & 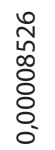 & $\begin{array}{l}\frac{0}{2} \\
\text { ñ } \\
\overline{0} \\
0 \\
0\end{array}$ & 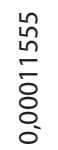 & 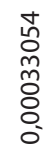 \\
\hline
\end{tabular}

- Para la aplicación del Modelo de Markowitz y del Método de las Restricciones se hace uso del programa Ms. Excel, específicamente del SOLVER, dando como resultado la frontera eficiente que se muestra en la Figura 2. En general, las restricciones utilizadas para este modelo se relacionan con la rentabilidad esperada del portafolio, la no negatividad de las ponderaciones y que la suma de las mismas sea igual a $100 \%$. Sin embargo, dependiendo del inversor, podría pensarse en restricciones adicionales que limiten la ponderación mínima y máxima de los activos elegibles, para que se dieran, por ejemplo, en un intervalo entre el $5 \%$ y $20 \%$, respectivamente.

- Teniendo en cuenta que se definió un perfil de riesgo bajo, se toman los portafolios que se calcularon para construir la frontera eficiente que tienen un riesgo menor de 3,3882 \%, considerando los rangos establecidos a partir de la diferencia entre los riesgos máximo y mínimo de la frontera, donde el punto de mínimo riesgo es de 0,4651\%, con una rentabilidad del 0,0375\%, conformado por 12 acciones (ECOPETROL, ÉXITO, PFAVAL, GRUPOAVAL, NUTRESA, CORFICOLCF, PFCORFICOL, EEB, BOGOTA, Isagen, ODINSA y PFHELMBANK) y el punto de máximo riesgo es de 10,6296\%, con una rentabilidad del 0,3989\%, conformado por una sola acción (CNEC). Como resultado, los portafolios que se consideran para la selección del portafolio final son 14 .
Figura 2. Frontera eficiente caso de aplicación

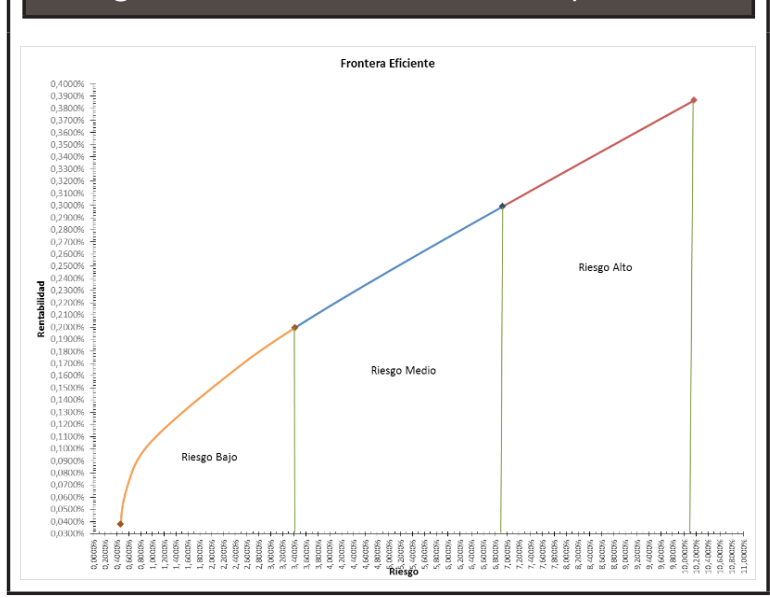

\subsection{Fase 2: optimización multicriterio}

\section{Selección del portafolio final}

Se establece un número máximo de 12 factores para el criterio de gobierno corporativo, 13 para el criterio de relaciones con colaboradores, 7 para el criterio de medio ambiente y 9 para el criterio de relaciones con la comunidad, de acuerdo con la siguiente tabla: 


\begin{tabular}{|c|c|c|c|c|c|c|c|c|c|c|c|c|c|c|}
\hline & 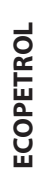 & 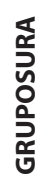 & $\underset{\text { 임 }}{\stackrel{ }{x}}$ & $\underset{\frac{1}{\alpha}}{\stackrel{\vec{L}}{\mathbf{L}}}$ & 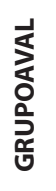 & 岂 & 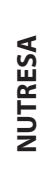 & 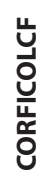 & 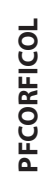 & 邑 & 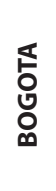 & $\begin{array}{l}\Xi \\
\stackrel{\Xi}{\Xi} \\
\underline{\Xi}\end{array}$ & 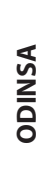 & 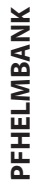 \\
\hline ECOPETROL & $\begin{array}{l}\infty \\
\infty \\
\varnothing \\
0 \\
0 \\
0\end{array}$ & $\begin{array}{l}\stackrel{\infty}{0} \\
\stackrel{0}{0} \\
\stackrel{0}{0} \\
0\end{array}$ & 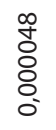 & $\begin{array}{l}\text { o } \\
0 \\
0 \\
0 \\
0\end{array}$ & $\begin{array}{l}\tilde{0} \\
\text { ò } \\
\text { o } \\
\text { o. }\end{array}$ & $\begin{array}{l}\text { 응 } \\
\stackrel{0}{0} \\
0 \\
0\end{array}$ & $\begin{array}{l}\tilde{m} \\
\stackrel{0}{0} \\
\stackrel{0}{0}\end{array}$ & $\begin{array}{l}\bar{m} \\
\text { ठ̀ } \\
\text { o. }\end{array}$ & $\begin{array}{l}\text { ¿े } \\
\text { ठ } \\
: \\
\circ\end{array}$ & $\begin{array}{l}\frac{a}{o} \\
\bar{o} \\
0 \\
0\end{array}$ & $\begin{array}{l}\frac{n}{0} \\
\frac{0}{0} \\
0\end{array}$ & $\begin{array}{l}\bar{\sigma} \\
\text { ठ } \\
\text { ¿ }\end{array}$ & $\begin{array}{l}\bar{\sigma} \\
\overline{0} \\
\overline{0}\end{array}$ & $\begin{array}{l}\text { ஃ্ } \\
\vdots \\
0 \\
0\end{array}$ \\
\hline GRUPOSURA & $\begin{array}{l}\infty \\
\stackrel{\infty}{\circ} \\
\stackrel{0}{0} \\
\text { : }\end{array}$ & $\begin{array}{l}\infty \\
\overline{0} \\
\overline{0} \\
0 \\
0\end{array}$ & 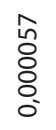 & $\begin{array}{l}\infty \\
\widetilde{0} \\
\stackrel{0}{0} \\
0 \\
0\end{array}$ & $\begin{array}{l}\text { ণे } \\
\text { ठे } \\
\text { : }\end{array}$ & $\begin{array}{l}\stackrel{+}{m} \\
\stackrel{\mathrm{o}}{\circ} \\
\stackrel{0}{0}\end{array}$ & $\begin{array}{l}\text { ơ } \\
0 \\
0 \\
0 \\
0\end{array}$ & $\begin{array}{l}\text { fे } \\
\text { ठ } \\
\text { : }\end{array}$ & $\begin{array}{l}0 \\
\overline{0} \\
\circ \\
0 \\
0\end{array}$ & $\begin{array}{l}0 \\
\check{0} \\
\stackrel{0}{0} \\
0 \\
0\end{array}$ & $\begin{array}{l}\stackrel{n}{o} \\
\overline{0} \\
\vdots \\
0\end{array}$ & $\begin{array}{l}\text { षे } \\
\text { ठ } \\
\text { : }\end{array}$ & $\begin{array}{l}\frac{m}{0} \\
\overline{0} \\
0 \\
0\end{array}$ & $\begin{array}{l}\infty \\
\stackrel{0}{0} \\
\stackrel{0}{\circ}\end{array}$ \\
\hline ÉXITO & 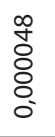 & $\begin{array}{l}\text { ñ } \\
\text { Oे } \\
\text { : }\end{array}$ & $\begin{array}{l}\text { స్ } \\
\text { ठ̀ } \\
\text { : }\end{array}$ & $\begin{array}{l}\text { 웅 } \\
\text { o. } \\
\text { o. }\end{array}$ & $\begin{array}{l}\overline{\tilde{o}} \\
\text { o } \\
\text { o. }\end{array}$ & $\begin{array}{l}\bar{\delta} \\
\text { ठ } \\
\text { o. }\end{array}$ & $\begin{array}{l}\text { ₹ } \\
\text { ठ } \\
0 \\
0\end{array}$ & 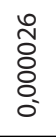 & 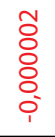 & $\begin{array}{l}0 \\
\overline{0} \\
\vdots \\
0\end{array}$ & 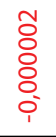 & $\begin{array}{l}\text { ơ } \\
\text { ठ } \\
\text { : } \\
\text { - }\end{array}$ & 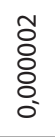 & 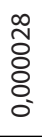 \\
\hline PFAVAL & $\begin{array}{l}\text { ơ } \\
0 \\
0 \\
0 \\
0\end{array}$ & 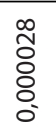 & $\begin{array}{l}\text { ơ } \\
0 \\
0 \\
0 \\
0\end{array}$ & $\begin{array}{l}\frac{a}{\tilde{c}} \\
\bar{\sigma} \\
0 \\
0\end{array}$ & 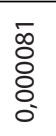 & $\begin{array}{l}n \\
\hat{0} \\
o \\
0 \\
0\end{array}$ & 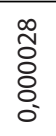 & $\begin{array}{l}\text { ñ } \\
\text { ठ̊ } \\
\text { o. }\end{array}$ & $\begin{array}{l}\frac{m}{\circ} \\
\text { o } \\
\text { o. }\end{array}$ & 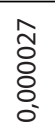 & $\begin{array}{l}\bar{\delta} \\
\text { ठ } \\
\text { o. }\end{array}$ & 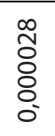 & $\begin{array}{l}\text { m. } \\
\text { ठ } \\
\text { o. }\end{array}$ & 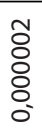 \\
\hline GRUPOAVAL & 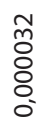 & 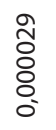 & $\begin{array}{l}\bar{m} \\
\overline{0} \\
\stackrel{0}{0} \\
0\end{array}$ & $\begin{array}{l}\bar{\infty} \\
\stackrel{0}{0} \\
0 \\
0\end{array}$ & $\begin{array}{l}\text { ₹ } \\
\bar{\delta} \\
0 \\
0\end{array}$ & 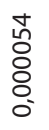 & 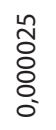 & $\begin{array}{l}\frac{n}{\delta} \\
\bar{\delta} \\
0 \\
0\end{array}$ & $\begin{array}{l}\text { ¿ } \\
\text { ¿ } \\
\text { : }\end{array}$ & $\begin{array}{l}\bar{\sigma} \\
\text { ठ } \\
\text { o. }\end{array}$ & 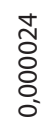 & $\begin{array}{l}a \\
\bar{o} \\
o \\
o \\
0\end{array}$ & $\begin{array}{l}\widetilde{0} \\
\text { ठ } \\
\text { ¿ }\end{array}$ & $\begin{array}{l}\text { ¿ } \\
\text { ठ } \\
\vdots \\
0\end{array}$ \\
\hline CNEC & 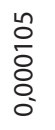 & $\begin{array}{l}\frac{m}{m} \\
\bar{o} \\
\frac{0}{0}\end{array}$ & $\begin{array}{l}\bar{\delta} \\
\text { ठ } \\
\text { : } \\
0\end{array}$ & $\begin{array}{l}\bar{o} \\
\text { ठ } \\
\text { : } \\
0\end{array}$ & 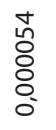 & $\begin{array}{l}\stackrel{a}{\grave{~}} \\
\frac{1}{0} \\
\text { o }\end{array}$ & $\begin{array}{l}\bar{ष} \\
\varnothing \\
\circ \\
\circ\end{array}$ & $\begin{array}{l}\bar{\delta} \\
\text { ठ̀ } \\
\text { o. }\end{array}$ & $\begin{array}{l}\bar{\delta} \\
\text { ठ } \\
\text { : }\end{array}$ & $\begin{array}{l}\bar{m} \\
\text { ठ̀ } \\
\text { o. }\end{array}$ & $\begin{array}{l}\text { : } \\
\text { ठ } \\
\stackrel{0}{0}\end{array}$ & 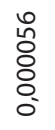 & $\begin{array}{l}\text { n. } \\
\text { ठ } \\
\text { o. }\end{array}$ & 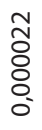 \\
\hline NUTRESA & $\begin{array}{l}\text { m. } \\
\stackrel{o}{o} \\
o \\
0\end{array}$ & $\begin{array}{l}\text { o } \\
\text { o } \\
\vdots \\
0\end{array}$ & 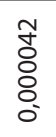 & 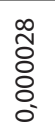 & 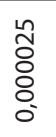 & $\begin{array}{l}\bar{\emptyset} \\
\vdots \\
\vdots \\
\circ\end{array}$ & $\begin{array}{l}\frac{\infty}{\bar{o}} \\
\frac{0}{0} \\
0\end{array}$ & $\begin{array}{l}\hat{\sigma} \\
\text { ठ̀ } \\
\text { o. }\end{array}$ & $\begin{array}{l}\text { m. } \\
\text { ठ } \\
\text { o }\end{array}$ & $\begin{array}{l}\hat{m} \\
\text { ò } \\
\text { o. }\end{array}$ & 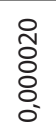 & 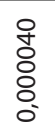 & $\begin{array}{l}\text { ठे } \\
\text { ठ } \\
\text { o. }\end{array}$ & $\begin{array}{l}\text { षे } \\
\text { ठ } \\
\text { : }\end{array}$ \\
\hline CORFICOLCF & 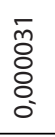 & $\begin{array}{l}\text { fे } \\
\text { o } \\
\text { Oे } \\
\text { o. }\end{array}$ & $\begin{array}{l}\stackrel{0}{0} \\
\text { ठ } \\
\text { ठ } \\
0\end{array}$ & 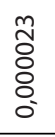 & $\begin{array}{l}\frac{n}{8} \\
\frac{0}{0} \\
0\end{array}$ & $\begin{array}{l}\bar{\sigma} \\
\text { ठ̀ } \\
\text { : } \\
\text { o. }\end{array}$ & $\begin{array}{l}\text { তे } \\
\text { ठ } \\
\text { ¿ }\end{array}$ & $\begin{array}{l}\text { o } \\
\text { ठ } \\
\text { ठ } \\
0\end{array}$ & $\begin{array}{l}\overline{\bar{o}} \\
\overline{0} \\
\overline{0}\end{array}$ & $\begin{array}{l}\text { No } \\
\text { o } \\
\text { o } \\
0\end{array}$ & $\begin{array}{l}\hat{\circ} \\
\text { ठ } \\
\text { : }\end{array}$ & $\begin{array}{l}\bar{m} \\
\text { ò } \\
\text { o } \\
\text { o. }\end{array}$ & $\begin{array}{l}\widetilde{0} \\
\text { ठ } \\
\text { ¿ }\end{array}$ & 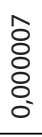 \\
\hline PFCORFICOL & 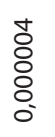 & $\begin{array}{l}0 \\
\overline{0} \\
\circ \\
0\end{array}$ & $\begin{array}{l}\text { ò } \\
\text { ه } \\
\text { i. }\end{array}$ & $\begin{array}{l}\frac{m}{o} \\
\frac{0}{0} \\
0\end{array}$ & $\begin{array}{l}\text { ¿ } \\
\varnothing \\
\circ \\
0\end{array}$ & $\begin{array}{l}\bar{y} \\
\text { ठ } \\
\text { o } \\
0\end{array}$ & $\begin{array}{l}\text { m. } \\
\text { ठ } \\
\text { : } \\
0\end{array}$ & $\begin{array}{l}\bar{o} \\
\overline{0} \\
0\end{array}$ & $\begin{array}{l}\frac{\pi}{\sigma} \\
\frac{0}{0} \\
0\end{array}$ & 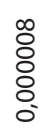 & $\begin{array}{l}\text { mo } \\
\text { ठ } \\
\text { o. }\end{array}$ & $\begin{array}{l}\bar{o} \\
\circ \\
\text { o } \\
\text { i. }\end{array}$ & 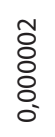 & $\begin{array}{l}\text { oे } \\
\text { ठ } \\
\text { ¿. } \\
\text { i. }\end{array}$ \\
\hline EEB & $\begin{array}{l}\frac{a}{0} \\
\bar{o} \\
0 \\
0\end{array}$ & $\begin{array}{l}0 \\
\check{0} \\
\vdots \\
0 \\
0\end{array}$ & $\begin{array}{l}0 \\
\stackrel{0}{0} \\
0 \\
0 \\
0\end{array}$ & 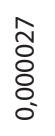 & $\begin{array}{l}\bar{\sigma} \\
\text { ठ } \\
\text { o. }\end{array}$ & $\begin{array}{l}\overline{\tilde{o}} \\
\text { } \\
0 \\
0\end{array}$ & $\begin{array}{l}\hat{0} \\
\text { o } \\
\text { o. }\end{array}$ & $\begin{array}{l}\text { ̃̃ } \\
\bar{o} \\
0 \\
0\end{array}$ & $\begin{array}{l}\infty \\
\stackrel{0}{0} \\
: \\
0 \\
0\end{array}$ & 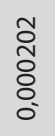 & $\begin{array}{l}\text { ¿ } \\
\text { ¿ } \\
\text { : }\end{array}$ & 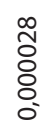 & 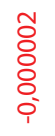 & $\begin{array}{l}\text { ¿ } \\
\text { ठ } \\
\vdots \\
\circ\end{array}$ \\
\hline BOGOTÁ & $\begin{array}{l}m \\
\bar{o} \\
0 \\
0 \\
0\end{array}$ & $\begin{array}{l}\frac{n}{0} \\
\overline{0} \\
\stackrel{0}{0}\end{array}$ & 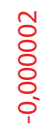 & $\begin{array}{l}\bar{\delta} \\
\overline{0} \\
\vdots \\
\circ\end{array}$ & 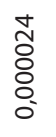 & $\begin{array}{l}\text { o } \\
\text { ठ } \\
\text { ठ } \\
0\end{array}$ & $\begin{array}{l}\stackrel{0}{~} \\
\text { ठ } \\
\text { ¿. }\end{array}$ & $\begin{array}{l}\hat{\circ} \\
\text { ठ } \\
\text { o. }\end{array}$ & 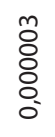 & 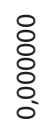 & 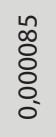 & $\begin{array}{l}\circ \\
\stackrel{0}{\circ} \\
\stackrel{0}{0} \\
\circ\end{array}$ & $\begin{array}{l}\bar{o} \\
\varnothing \\
\circ \\
\circ\end{array}$ & 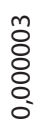 \\
\hline Isagen & 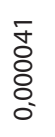 & $\begin{array}{l}\text { षे } \\
\text { ठ } \\
\text { O. }\end{array}$ & 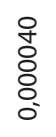 & $\begin{array}{l}\infty \\
\widetilde{o} \\
\stackrel{0}{0} \\
\stackrel{0}{0}\end{array}$ & $\begin{array}{l}a \\
\bar{o} \\
\text { o } \\
\text { o. }\end{array}$ & 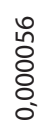 & $\begin{array}{l}\text { ơ } \\
0 \\
0 \\
0 \\
0\end{array}$ & $\begin{array}{l}\bar{m} \\
\text { Oे } \\
\text { o. }\end{array}$ & $\begin{array}{l}\bar{\sigma} \\
\text { ठ } \\
\text { : } \\
\text { i. }\end{array}$ & 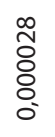 & $\begin{array}{l}0 \\
\overline{0} \\
\circ \\
0 \\
0\end{array}$ & $\begin{array}{l}\frac{n}{0} \\
\frac{0}{0} \\
0\end{array}$ & $\begin{array}{l}\bar{o} \\
\bar{o} \\
0 \\
0\end{array}$ & 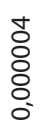 \\
\hline ODINSA & $\begin{array}{l}\overline{\bar{o}} \\
\overline{0} \\
\overline{0}\end{array}$ & $\begin{array}{l}\frac{m}{0} \\
\vdots \\
0 \\
0\end{array}$ & $\begin{array}{l}\text { ठิ } \\
\text { ठ } \\
\text { - }\end{array}$ & 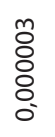 & $\begin{array}{l}\text { ठे } \\
\text { ठ } \\
\text { ¿ } \\
0\end{array}$ & $\begin{array}{l}\text { \%े } \\
\text { ठ } \\
\text { o } \\
0\end{array}$ & $\begin{array}{l}\text { ̊े } \\
\text { ठे } \\
\text { ठ } \\
0\end{array}$ & $\begin{array}{l}\text { ¿े } \\
\text { ठ } \\
\text { ¿. }\end{array}$ & $\begin{array}{l}\text { ठे } \\
\text { ठ } \\
\text { : }\end{array}$ & $\begin{array}{l}\text { ô } \\
\text { ठ } \\
\text { i. }\end{array}$ & $\begin{array}{l}\overline{0} \\
\bar{o} \\
\text { : }\end{array}$ & $\begin{array}{l}\overline{\bar{o}} \\
\overline{0} \\
\text { : }\end{array}$ & $\begin{array}{l}\frac{0}{\overline{0}} \\
\frac{0}{0} \\
0\end{array}$ & 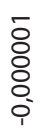 \\
\hline PFHELMBANK & $\begin{array}{l}8 \\
0 \\
0 \\
0 \\
0\end{array}$ & $\begin{array}{l}\infty \\
\stackrel{0}{0} \\
\stackrel{0}{0} \\
0\end{array}$ & 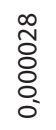 & 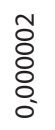 & 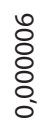 & 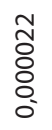 & $\begin{array}{l}\text { ठ } \\
0 \\
0 \\
0 \\
0\end{array}$ & $\begin{array}{l}\hat{\circ} \\
\text { ठ } \\
\text { : }\end{array}$ & $\begin{array}{l}\text { वे } \\
\text { ठ } \\
\text { ¿ }\end{array}$ & $\begin{array}{l}\text { ¿ } \\
\text { ठ } \\
\text { : }\end{array}$ & 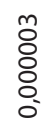 & $\begin{array}{l}\text { ¿े } \\
\text { ठ } \\
\stackrel{0}{\circ}\end{array}$ & $\begin{array}{l}\bar{o} \\
\text { ¿ } \\
\text { i. }\end{array}$ & $\begin{array}{l}\bar{m} \\
\text { Oे } \\
\text { o } \\
0\end{array}$ \\
\hline
\end{tabular}




\begin{tabular}{|c|c|}
\hline Criterio & Factor \\
\hline \multirow{12}{*}{$\begin{array}{l}\text { 1. Gobierno } \\
\text { Corporativo }\end{array}$} & 1.1. La empresa declara su estructura de gobierno corporativo. \\
\hline & $\begin{array}{l}\text { 1.2. Dentro de los comités de apoyo, si existen, hay por lo menos uno que apoye la gestión de buen gobierno y/o } \\
\text { sostenibilidad de la empresa. }\end{array}$ \\
\hline & $\begin{array}{l}\text { 1.3. Dentro de los comités de apoyo, si existen, hay por lo menos uno que apoye la gestión relacionada con sus } \\
\text { colaboradores. }\end{array}$ \\
\hline & $\begin{array}{l}\text { 1.4. Dentro de los comités de apoyo, si existe, hay por lo menos uno que apoye la gestión ética y de transparencia } \\
\text { de la empresa. }\end{array}$ \\
\hline & 1.5. La empresa declara cuáles son los documentos y/o reglas que guían a los órganos de gobierno. \\
\hline & 1.6. La empresa declara que cuenta con un Código de Gobierno Corporativo. \\
\hline & $\begin{array}{l}\text { 1.7. La empresa declara que cuenta con un código de ética y/o de buena conducta que apoyan el proceso ético } \\
\text { dentro y fuera de la organización. }\end{array}$ \\
\hline & 1.8. La empresa declara que cuenta con canales éticos. \\
\hline & 1.9. La empresa declara que cuenta con documentos que rechacen toda forma de corrupción y/o fraude. \\
\hline & 1.10. La empresa declara que cuenta con programas de lucha contra la corrupción. \\
\hline & 1.11. La empresa declara que cuenta con un sistema, programa y/o actividad para la gestión de riesgos. \\
\hline & $\begin{array}{l}\text { 1.12. La empresa cuenta con reconocimientos y/o certificaciones que acrediten su compromiso con prácticas de } \\
\text { Buen Gobierno Corporativo. }\end{array}$ \\
\hline \multirow{13}{*}{$\begin{array}{l}\text { 2. Relaciones } \\
\text { con } \\
\text { Colaboradores }\end{array}$} & $\begin{array}{l}\text { 2.1. Dentro del Informe se desglosa el colectivo de trabajadores por tipo de empleo, por contrato, por edad, por } \\
\text { género y por región. }\end{array}$ \\
\hline & $\begin{array}{l}\text { 2.2. La empresa declara que cuenta con políticas o procedimientos claros para la incorporación de talento humano } \\
\text { a la organización. }\end{array}$ \\
\hline & 2.3. La empresa declara que cuenta con políticas o procedimientos de compensación para garantizar equidad interna. \\
\hline & $\begin{array}{l}\text { 2.4. La empresa declara que cuenta con beneficios sociales extralegales para sus trabajadores que propendan por } \\
\text { un ambiente laboral saludable. }\end{array}$ \\
\hline & 2.5. La empresa declara que otorga beneficios a sus trabajadores y familiares relacionados con asuntos pensionales. \\
\hline & 2.6. La empresa declara que realiza mediciones del clima laboral dentro de la organización. \\
\hline & 2.7. La empresa declara que cuenta con programas de formación, desarrollo y crecimiento para su talento humano. \\
\hline & $\begin{array}{l}\text { 2.8. La empresa declara que cuenta con convenios colectivos para fomentar buenas relaciones entre la empresa y } \\
\text { trabajadores. }\end{array}$ \\
\hline & 2.9. La empresa declara que garantiza a sus trabajadores el derecho a asociarse. \\
\hline & 2.10. La empresa declara que cuenta con un comité que garantiza una sana convivencia entre trabajadores. \\
\hline & $\begin{array}{l}\text { 2.11. La empresa cuenta con programas de educación, formación, asesoramiento, prevención y control en salud y } \\
\text { seguridad ocupacional. }\end{array}$ \\
\hline & 2.12. La empresa declara su apoyo a la erradicación de trabajo infantil y trabajo forzoso. \\
\hline & $\begin{array}{l}\text { 2.13. La empresa cuenta con reconocimientos y/o certificaciones que acrediten su compromiso con prácticas que } \\
\text { garanticen adecuadas relaciones con sus colaboradores. }\end{array}$ \\
\hline \multirow{7}{*}{$\begin{array}{l}\text { 3. Medio } \\
\text { ambiente }\end{array}$} & 3.1. La empresa declara que cuenta con un sistema, política y/o plan general para la gestión ambiental. \\
\hline & 3.2. La empresa declara que cuenta con programas, políticas y/o estrategias para la gestión eficiente de recursos. \\
\hline & $\begin{array}{l}\text { 3.3. La empresa declara que cuenta con programas, políticas y/o estrategias para la mitigación de efectos relaciona- } \\
\text { dos con cambio climático. }\end{array}$ \\
\hline & 3.4. La empresa declara que cuenta con programas, políticas y/o estrategias para la conservación de la biodiversidad. \\
\hline & $\begin{array}{l}\text { 3.5. La empresa cuenta con programas de educación y/o capacitación en temas relacionados con medio ambiente } \\
\text { dentro y/o fuera de la organización. }\end{array}$ \\
\hline & 3.6. La empresa declara que cuenta con aliados estratégicos para la gestión medioambiental. \\
\hline & $\begin{array}{l}\text { 3.7. La empresa cuenta con reconocimientos y/o certificaciones que acrediten su compromiso con prácticas de } \\
\text { gestión ambiental. }\end{array}$ \\
\hline
\end{tabular}


Tabla 7. Factores establecidos para los criterios de RSE

\begin{tabular}{|c|c|}
\hline Criterio & Factor \\
\hline \multirow{9}{*}{$\begin{array}{l}\text { 4. Relaciones } \\
\text { con la } \\
\text { comunidad }\end{array}$} & $\begin{array}{l}\text { 4.1. La empresa declara que cuenta con políticas y/o estrategias generales para asegurar una gestión responsable } \\
\text { de las relaciones de la empresa con las comunidades en las cuales opera. }\end{array}$ \\
\hline & $\begin{array}{l}\text { 4.2. La empresa declara que cuenta con programas y/o proyectos para garantizar a las comunidades donde opera, } \\
\text { derecho a la salud. }\end{array}$ \\
\hline & $\begin{array}{l}\text { 4.3. La empresa declara que cuenta con programas y/o proyectos para garantizar a las comunidades donde opera, } \\
\text { derecho a la educación. }\end{array}$ \\
\hline & 4.4. La empresa declara que cuenta con programas y/o proyectos para promover la cultura y/o el deporte. \\
\hline & $\begin{array}{l}\text { 4.5. La empresa declara que cuenta con programas y/o proyectos para garantizar el desarrollo productivo de las } \\
\text { comunidades donde opera. }\end{array}$ \\
\hline & 4.6. La empresa declara que cuenta con aliados estratégicos para la gestión social en las comunidades donde opera \\
\hline & $\begin{array}{l}\text { 4.7. La empresa declara que se apoya en una fundación u organización para promover su gestión social en las } \\
\text { comunidades donde opera }\end{array}$ \\
\hline & $\begin{array}{l}\text { 4.8. La empresa declara que cuenta con un programa de voluntariado que vincula a sus trabajadores y familias en } \\
\text { su compromiso social con las comunidades donde opera. }\end{array}$ \\
\hline & $\begin{array}{l}\text { 4.9. La empresa cuenta con reconocimientos y/o certificaciones que acrediten su compromiso con prácticas de } \\
\text { gestión social en las comunidades donde opera. }\end{array}$ \\
\hline
\end{tabular}

A la luz de estos factores se establece para cada una de las empresas emisoras de las acciones seleccionadas, un porcentaje de cumplimiento general frente a los criterios de gobierno corporativo, relaciones con colaboradores, medio ambiente y relaciones con la comunidad, como se muestra a continuación:

Tabla 8. Porcentaje de cumplimiento de las empresas emisoras de la acciones seleccionadas frente a los criterios de RSE definidos

\begin{tabular}{|c|c|c|c|c|}
\hline Acción & $\begin{array}{c}\text { Gobierno } \\
\text { corporativo }\end{array}$ & $\begin{array}{l}\text { Relaciones con } \\
\text { colaboradores }\end{array}$ & Medio ambiente & $\begin{array}{l}\text { Relaciones con la } \\
\text { comunidad }\end{array}$ \\
\hline Ecopetrol & 100 & 100 & 100 & 77,78 \\
\hline $\begin{array}{l}\text { Grupo Inversiones } \\
\text { Suramericana }\end{array}$ & 83,33 & 53,85 & 71,43 & 66,67 \\
\hline Almacenes Éxito S.A. & 100 & 92,31 & 85,71 & 77,78 \\
\hline $\begin{array}{c}\text { Grupo Aval Acciones y } \\
\text { Valores S.A. }\end{array}$ & 50 & 23,08 & 42,86 & 66,67 \\
\hline Canacol Energy Ltd & 50 & 15,38 & 57,14 & 33,33 \\
\hline Grupo Nutresa S.A. & 75 & 76,92 & 100 & 88,89 \\
\hline $\begin{array}{c}\text { Corporación Financiera } \\
\text { Colombiana S.A. }\end{array}$ & 58,33 & 61,54 & 100 & 55,56 \\
\hline $\begin{array}{c}\text { Empresa de Energía de } \\
\text { Bogotá S.A. E.S.P. }\end{array}$ & 91,67 & 92,31 & 100 & 66,67 \\
\hline Banco de Bogotá S.A. & 41,67 & 38,46 & 42,86 & 88,89 \\
\hline Isagen S.A. E.S.P. & 75 & 84,62 & 100 & 77,78 \\
\hline $\begin{array}{c}\text { Organización de Ingeniería } \\
\text { Internacional S.A. }\end{array}$ & 58,33 & 46,15 & 71,43 & 44,44 \\
\hline Helm Bank S.A. & 50 & 38,46 & 71,43 & 55,56 \\
\hline
\end{tabular}




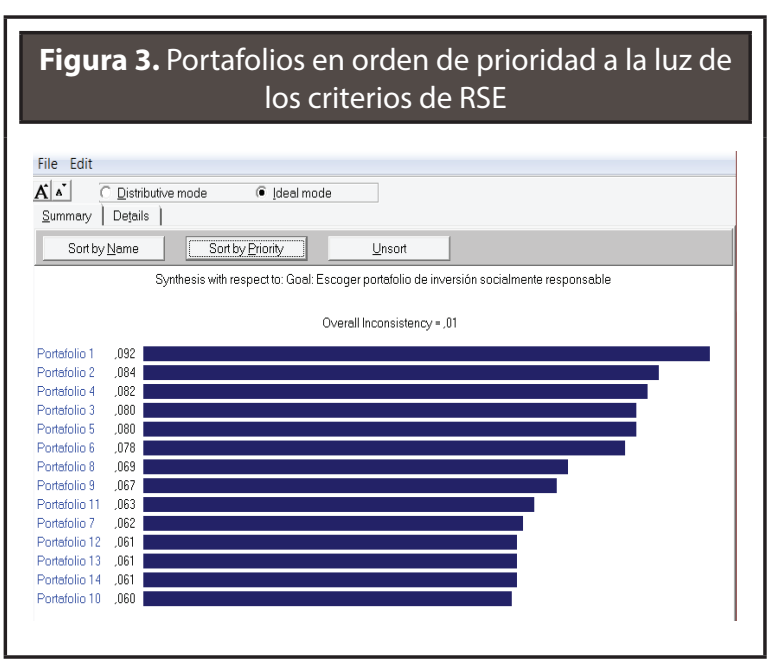

Donde empresas como Ecopetrol, Almacenes Éxito S.A. y Empresa de Energía de Bogotá S.A. E.S.P. muestran un porcentaje de cumplimiento mayor al $90 \%$ en los criterios de gobierno corporativo y relaciones con colaboradores. Igualmente, en el criterio de medio ambiente, las empresas que cuentan con un porcentaje de cumplimiento mayor del $90 \%$ son Ecopetrol, Grupo Nutresa S.A., Corporación Financiera Colombiana S.A., Empresa de Energía de Bogotá S.A. E.S.P., e Isagen S.A. E.S.P.; mientras que en el criterio de relaciones con la comunidad, las empresas que cuentan con un porcentaje de cumplimiento mayor al 80 \% (dado que no alcanzan el $90 \%$ ) son Grupo Nutresa S.A. y Banco de Bogotá S.A.

- Como producto de la aplicación del Proceso Analítico Jerárquico (AHP) que lleva a cabo el software Expert Choice, se presenta en la Figura 3 los portafolios escogidos para la decisión final en orden de prioridad bajo consideraciones de RSE.

- Consecuente con el procedimiento de selección de portafolios propuesto en el presente trabajo, se establece que el portafolio 1 (el de mínimo riesgo en la frontera eficiente) es el que puede cumplir con el perfil socialmente responsable de bajo riesgo definido anteriormente, representando para el inversor una rentabilidad del $0,0375 \%$ a un nivel de riesgo del 0,4652 \%. Para ello, el capital invertido en este portafolio tendría la siguiente composición:

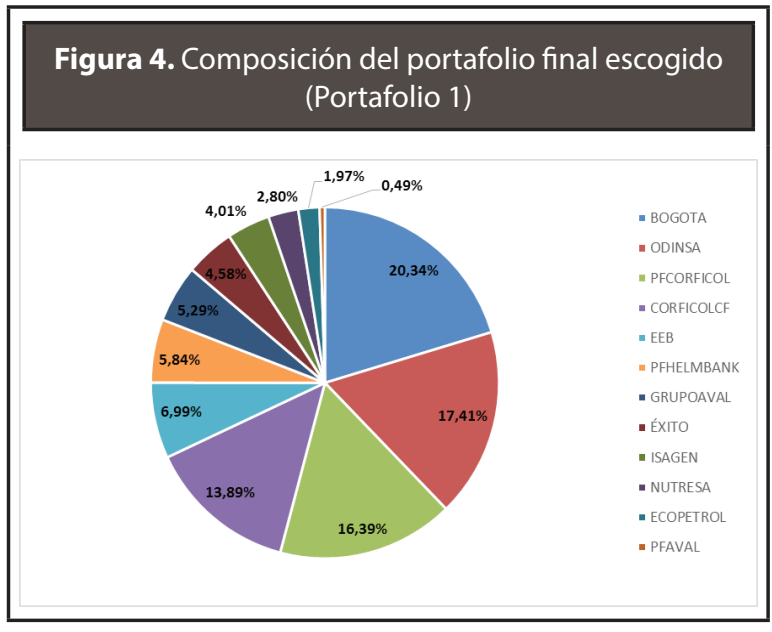

- Pese a que los portafolios 2, 4, 3 y 5, priorizados a la luz de los criterios de RSE definidos, cumplen con el perfil de un inversor socialmente responsable de bajo riesgo, su nivel de riesgo aumenta progresivamente, así como su rentabilidad esperada. El Portafolio 2 por su parte, representa una rentabilidad del 0,0500 \% a un nivel de riesgo del 0,4845\%, donde se reestructura la participación de las acciones, disminuyendo su participación acciones como ECOPETROL, GRUPOAVAL, NUTRESA, CORFICOLCF, PFCORFICOL, EEB y ODINSA, mientras que ÉXITO, BOGOTÁ, Isagen Y PFHELMBANK aumentan su participación, así como CNEC se incluye dentro de las opciones de inversión y se omite PFAVAL, tal como se muestra en la Figura 5:

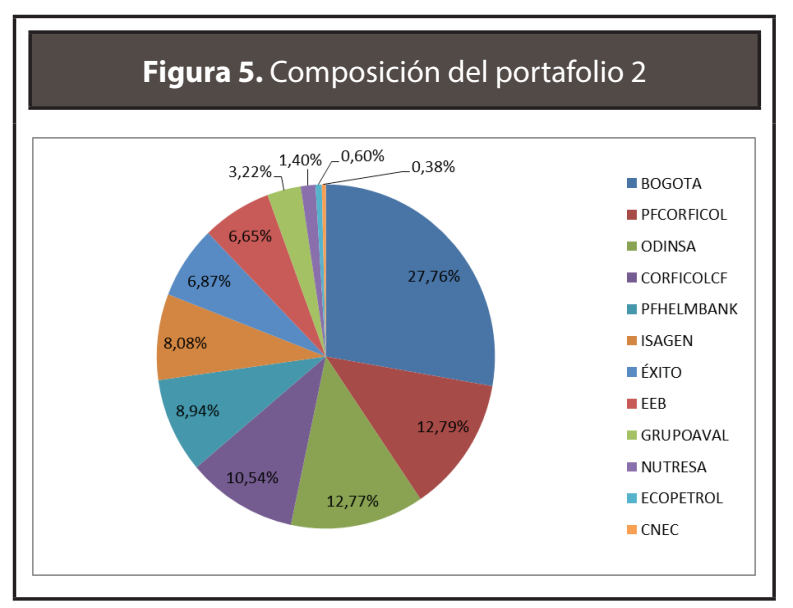




\section{DISCUSIÓN}

El proceso para la selección de portafolios de inversión, así como otros procesos para la toma de decisiones han sido considerados bajo la premisa de que en un problema decisional se pueden presentar diversas alternativas de solución, y escoger entre una de ellas requiere de la identificación del objetivo que se desea alcanzar.

No obstante, hoy en día estos problemas son tan complejos y demandan una visión integral de los mismos, que para su análisis y solución se deben considerar varios objetivos. Es por ello que, en un intento por modelar el problema, se han desarrollado un sinnúmero de herramientas, métodos y técnicas científicas que buscan la optimización de estos objetivos que frecuentemente se encuentran en conflicto; introduciendo el concepto de programación multiobjetivo y decisión multicriterio con sus siglas en inglés MCDM (Multiple Criteria Decision Making).

Las técnicas multiobjetivo y multicriterio han tenido sus bases en el problema decisional; sin embargo, su uso está influenciado por la información que posea el decisor, sus limitaciones, sus preferencias y los objetivos que persiga. En el caso de técnicas multiobjetivo para la selección de portafolios de inversión, la formulación del problema está basada en supuestos cuantitativos o que se puedan ajustar a principios matemáticos, por ejemplo las medidas de rentabilidad y riesgo. No obstante, estas técnicas en diversas ocasiones no representan totalmente lo que desea el inversor dado que algunas de sus preferencias no se pueden modelar matemáticamente con facilidad, por ejemplo sus intereses en cuestiones relacionadas con RSE. Por ello se pueden encontrar en la literatura técnicas multicriterio que han contribuido o, por lo menos, han fundamentado con elementos científicos, el proceso de toma de decisiones que dependen de distintos criterios o atributos de tipo cualitativo, cuantitativo o de una mezcla de ambos y que aportan mejoras distintivas para satisfacer, tanto como sea posible, las preferencias del inversor.
Por su parte, la Responsabilidad Social Empresarial es un tema que cada día cobra mayor importancia, no solo en el ámbito empresarial sino en cuestiones financieras, especialmente en aquellas relacionadas con decisiones de inversión. Con el paso del tiempo ha ido creciendo la convicción de que las prácticas socialmente responsables de las empresas contribuyen a la construcción de un mercado global más estable, equitativo e incluyente, y que fomentan sociedades más prósperas. Además, se considera que estas prácticas pueden reflejar un aumento de la rentabilidad financiera a largo plazo y un menor riesgo.

Es por eso que el procedimiento descrito en este artículo para la selección de portafolios de inversión con responsabilidad social empresarial a partir de técnicas multiobjetivo y multicriterio, constituye una herramienta para apoyar a los inversores socialmente responsables en la búsqueda de una cartera que pueda cumplir con sus expectativas, tanto económicas (rentabilidad y riesgo), como aquellas relacionadas con particularidades ambientales, sociales y/o éticas de las empresas emisoras de títulos valores (gobierno corporativo, relaciones laborales, medioambiente y relaciones con la comunidad).

Así las cosas, y atendiendo a los resultados de la aplicación del procedimiento para el caso de la Bolsa de Valores de Colombia, donde el portafolio que mejor cumple con los criterios establecidos en este artículo para RSE también es el de mínimo riesgo; se podría percibir relación directa, en la selección de portafolios, entre el cumplimiento de objetivos sociales, medioambientales y éticos, y la optimización de objetivos económicos (en este caso con la minimización del riesgo). Esta apreciación se hace teniendo en cuenta que el perfil definido antes de la aplicación del procedimiento fue socialmente responsable y de bajo riesgo.

\section{Símbolos utilizados}

$\sigma_{i j} \quad$ Covarianza entre las acciones $i$ y $j$

$\sigma_{i} \quad$ Desviación estándar del título $i$

$\sigma\left(R_{p}\right)$ Desviación estándar del portafolio

$\sigma_{i}^{2} \quad$ Varianza del título $i$ 
$\sigma^{2}\left(R_{p}\right)$ Varianza del portafolio

$P_{t} \quad$ Precio de cierre del título al final del período $t$

$P_{t-1} \quad$ Precio de cierre del título al inicio del período $t$

$r_{t} \quad$ Rentabilidad del título en el período $t$

$r_{i t} \quad$ Rentabilidad del título valor $i$ en el periodo $t$

$r_{j t} \quad$ Rentabilidad del título valor $j$ en el periodo $t$

$R_{i} \quad$ Rentabilidad promedio del título valor $i$

$R_{j} \quad$ Rentabilidad promedio del título valor $j$

$T \quad$ Número de rentabilidades observadas

\section{REFERENCIAS}

Antomil, J.; Cañal, V. y Rodríguez, M.V. (2008). La selección de carteras socialmente responsables: Revisión crítica de la literatura. Revista Electrónica de Comunicaciones y Trabajos de ASEPUMA, ISSN 1575605X, (9), pp. 147-172.

Barnett, M. L. y Salomón, R. M. (2006). Beyond Dichotomy: the Curvilinear Relationship Between Social Responsibility and Financial Performance. Strategic Management Journal, 27(11), September, pp. 11011122.

Barrachini, C. (2004). An Ethical Investments Evaluation for Portfolio Selection. [pdf] Electronic Journal of Business, Ethics and Organization Studies. Disponible en: https://jyx.jyu.fi/dspace/ handle/123456789/25347, [Consultado el 14 de abril de 2013].

Basso, A. y Funari, S. (2003). Measuring the Performance of Ethical Mutual Funds: a DEA Approach. Journal of the Operational Research Society, 54 (5), May, pp. 521-531.

Bilbao-Terol, A. M. et al. (2009). Selección de carteras de fondos de inversión socialmente responsables mediante programación por metas con tecnología difusa. Revista Electrónica de Comunicaciones y Trabajos de ASEPUMA, (10), pp. 29-57.

Branke, B. et al. (2009). Portfolio Optimization with an Envelope-Based Multi-Objective Evolutionary Algorithm. Journal European Research, (199), May, pp. 684-693.

Charnes, A. y Cooper, W. (1961). Management Models and Industrial Applications of Linear Programming. Management Science, 1(4), October, pp. 38-91.

Fernández-Romero, J. E. (2008) Modelos de optimización de portafolios: un estudio comparativo basado en simulaciones computacionales. (Trabajo de Grado). Escuela Politécnica Nacional.

Fontalvo, T. J.; Morelos, J. y Vergara-Schmalbch, J.C. (2012). Aplicación del Método de Decisión Multicriterio UTASTAR para la Selección de Portafolios de Inversión. Global Conference on Business and Finance Proceedings (22-25, Mayo: San José, Costa Rica), 7(2), pp. 961-966.

Franco-Arbeláez, L.; Avendaño-Rúa, C. y Barbutín-Díaz, H. (2011). Modelo de Markowitz y Modelo de BlackLitterman en la Optimización de Portafolios de Inversión. Revista Tecno Lógicas, (26), junio, pp. 7188.

Hallerbach, W., et al. (2004). A Framework for Managing a Portfolio of Socially Responsible Investments. European Journal of Operational Research, 153(2), March, pp. 517-529.

Kempf, A. y Osthoff, P. (2008). "SRI Funds: Nomen est Omen". Journal of Business Finance \& Accounting, 35 (9-10), November-December, pp. 1276-1294.

Mendizábal, A.; Miera, L.M. y Zubia, M. (2002) El Modelo de Markowitzenla Gestión de Carteras. [pdf] disponible en: http://addi.ehu.es/bitstream/10810/7000/1/ CdG_212.pdf [Consultado el 14 de abril de 2013].

Minutti, C. (2010) Métodos de optimización en la construcción de portafolios. (Tesis de licenciatura). Universidad Autónoma Chapingo.

Subbu, P., et al. (2005). Multiobjective Financial Portfolio Design: A Hybrid Evolutionary Approach. Congress on Evolutionary Computation IEEE, ISBN: 0-78039363-5, 2, September, pp. 1722- 1729.

Zavala, J. et al. (2009). Modelo matemático multiobjetivo para la selección de una cartera de inversión en la bolsa mexicana de valores. Congreso Internacional de Cómputo en Optimización y Software- CICOS (1720, noviembre: UAEM México D.F.), pp. 396-408.

\section{PARA CITAR ESTE ARTÍCULO / TO REFERENCE THIS ARTICLE / PARA CITAR ESTE ARTIGO /}

Bernard-Suárez, L.M.; Ortiz-Pimiento, N.R.; Duarte-Duarte, J.B. (2015). Selección de portafolios de inversión socialmente responsables usando el método de las restricciones y la técnica multicriterio Proceso Analítico Jerárquico. Revista EIA, 12(24), Julio-diciembre, pp. 71-85. [Online]. Disponible en: DOI: http:/dx.doi.org/10.14508/reia.2015.12.24.71-85 